\title{
Sensitivity of Predicted Maximum Bending Moment to IBC Design Response Spectrum Parameters
}

\author{
Tariq M. Nahhas \\ Department of Civil Engineering, Umm Al-Qura University, PO Box 16222, Makkah, Saudi Arabia \\ Received 1 July 2007; accepted 5 May 2008

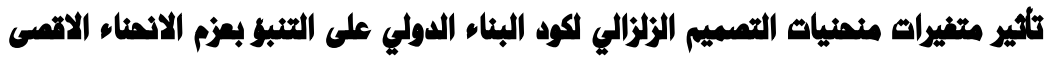 \\ / / طارق بن محمد نحاس

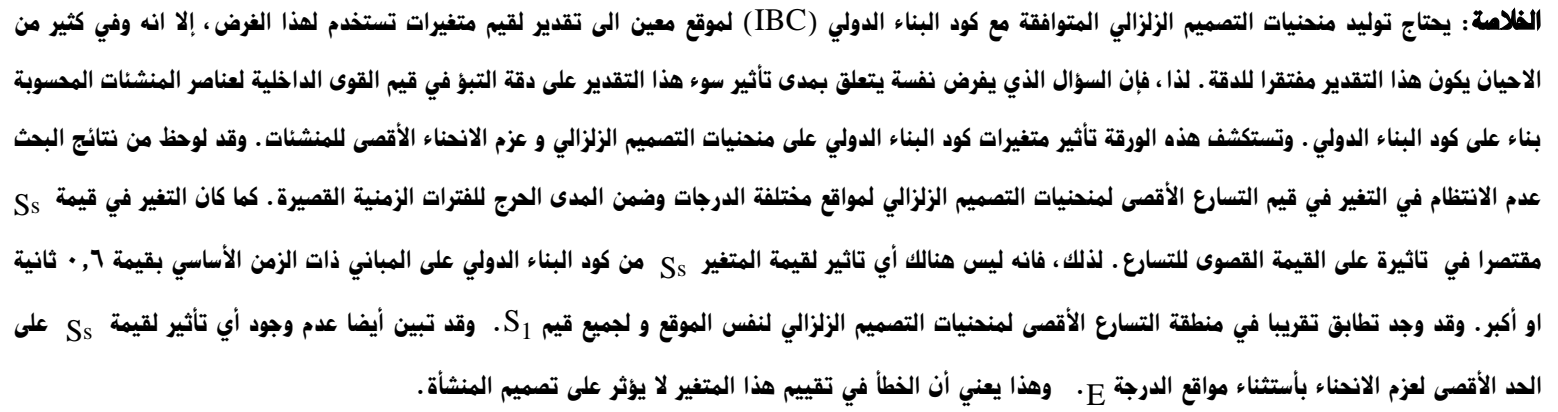 \\ الهزدات الهنامية: النذجة الإنشائية، البباني البتعددة الأدوار، منحنيات التصميم الزلزالي،عزم الانحناء الأقصى.
}

\begin{abstract}
The parameters used to generate IBC (International Building Code) compliant design response spectra are specified only approximately for a given site in most cases and values may even be erroneous. So, the question arises about the effect of approximation or error in the values of these parameters on the predicted internal forces in the structural elements of a building calculated on the basis of the provisions of IBC. This paper explores this issue and presents the sensitivities of design response spectra and maximum moments induced in the structure to these IBC parameters. Within the critical range of short time periods, the variation in peak acceleration of design response spectra for various site classes is found non-uniform. Only peak acceleration is affected by varying $S_{S}$. Thus, for buildings with the fundamental time period of around 0.6 sec and greater, the parameter $\mathrm{S}_{\mathrm{S}}$ of IBC is immaterial. Also, for a given site class, the design response spectra are almost identical in the peak acceleration region for all values of $S_{1}$. The maximum moment is insensitive to $S_{S}$ except for the site class E. This implies that any error in the evaluation of this parameter will not affect the design of the structure.
\end{abstract}

Keywords: Structural modeling, IBC, Multi-story building, Response spectrum, Moment capacity

\section{Introduction}

International Building Code (International Code Council, 2003) has provisions to generate design response spectra for response spectrum analysis of multi-story building structures. To comply with these provisions, response spectrum analysis is performed using a design response spectrum based on parameters specified by the code. Internal forces obtained by such a code compliant analysis are in fact predicted internal forces that may occur when the building is subjected to an earthquake represented by the design response spectrum. However, the parameters that control the shape of the design response spectrum are based on soil stiffness and seismic activity of the region and therefore these parameters can only be evaluated approximately. Since the structural design of a

Corresponding author’s e-mail: tnahhas@uqu.edu.sa building is based on the predicted internal forces in its structural members, the question arises about the effect of error or approximation in the evaluation of the IBC parameters on the predicted internal forces. This question becomes even more important when a number of design alternatives are to be analyzed. This question can only be answered by assessing the sensitivity of the predicted internal forces to these code parameters. Such sensitivity data that can show the effect of approximation or error on the predicted internal forces is the focus of this paper.

The sensitivity of the predicted internal forces to the code parameters is important for structural designers and engineers as well as for code developers and the authorities trying to ensure safer earthquake resistant buildings. Adequacy of building codes is an issue of concern in most countries of the world. Such sensitivity data are important to determine the adequacy of seismic design provisions of building codes and to gain confidence in its application to 
real-world problems. Despite the importance of this issue and despite the widespread publications in the area of seismic analysis of multi-story buildings, like (Hooper, 2006), (Anagnostopoulos and Demopoulos, 2003), (Wilkinson and Thambiratnam, 2001) and (Chopra and Goel, 2001) and many others, no published work seems to exist on this issue. This issue, therefore, has been investigated in this paper to determine the sensitivity of the predicted structural response of multi-story buildings to design response spectra parameters specified in the code. IBC 2003 was selected for this study because this code has replaced UBC 1997 (International Conference of Building Officials, 1997), has become popular in USA and many developing countries where it has been used as a base code.

To establish the sensitivities as described above, the effects of IBC parameters on the shape of generated design response spectra were determined. It was important to do so because if the design response spectrum is insensitive to the IBC parameters, the predicted internal moments based on the design response spectrum will also be insensitive. Therefore, this paper first presents the curves showing the variations in the shapes of design response spectra due to the variations in the IBC parameters. Next, the sensitivity of internal forces is generated. Only the maximum bending moment is considered. Shear forces in the structural members were found to have similar sensitivity and are not included in this paper. The maximum predicted bending moments are evaluated for the case of a simple structure of academic nature and then for three cases of different low rise buildings that are more common for residential purposes. For all the four cases, a series of design response spectra are generated by varying IBC parameters and the sensitivity curves are presented.

To determine if a given structural element in a building will be able to resist the bending moment produced by the code-compliant design response spectrum, it is necessary to calculate the moment capacity of the element. Since the hand calculations of the moment capacity of a large number of structural members were not practical for obtaining results from the analysis of a number of buildings, an EXCEL spreadsheet program was developed to calculate the moment capacity for any beam or column. The assumptions made to calculate the full ultimate moment capacity were based on the ultimate strength design of reinforced concrete sections in bending.

Results have been presented graphically to show the sensitivity of the predicted bending moment induced due to the seismic load to the variations in design response spectra. These graphs clearly show similar trend for all cases. These data are helpful to the structural designers in estimating how the design of the structural elements of a building will be affected by changes to the input design response spectra. Also, the data will be helpful in improving the code provisions in the future.

\section{3-D Structural Modeling}

To produce the sensitivity data as described above, a repeated modeling of three-dimensional structure of multi-story buildings for varying values of IBC parameters is required. The common modeling approach of the available structural analysis software packages requires visualization of the three-dimensional wire frame structural model of a given building before preparing the input data. Due to the huge amount of data involved with threedimensional structural models of multi-story buildings, the modeling process using the available software packages becomes laborious, time-consuming, and errorprone. To generate the structural models of multi-story buildings with confidence, easy and error-free modeling is required. For this reason, a specialized pre-processor software package for multi-story buildings called PLAN23D (Engineering Optimization Software, 2007) was used in conjunction with SAP2000 (Computers \& Structures Inc., 2005) was used for structural analysis.

The philosophy of PLAN23D is different from all software packages available for structural analysis and modeling. This software offers a conceptually different new approach without a prior visualization of the three-dimensional structural model. It makes all required input data related to the floor plan of the building. Therefore, the user's role in identification of elements, joints, bays or columns and labeling them for the sake of preparing the input data is completely eliminated. Instead, all input will solely be related to the floor plan. All the required data are input through a few clicks of the mouse pointer. It calculates all the distributed loads acting on the beams due to the slab dead and live loads including the wall loads and generates IBC design response spectra. Section specification is quite easy and it also relieves the user from worrying about the local axes for specifying the correct orientation of the columns. In addition, it produces ready-to-go data files for several structural analysis software packages.

In this work, using PLAN23D, ready-to-go input data files were generated for SAP2000. The choice of SAP2000 was mainly due to its availability. Any other structural analysis software package will do the job equally well in conjunction with PLAN23D. The effectiveness of this approach was validated by performing the structural analysis of multi-story buildings using SAP2000 without using PLAN23D and then repeating the analysis for the same building using SAP2000 in conjunction with PLAN23D. Comparing the time, effort and accuracy of results, it was validated and verified that the time and effort required to perform the analysis reduce drastically by orders of magnitudes (Nahhas and Imam, 2001).

\section{IBC Design Response Spectra}

In this section, IBC provisions for the design response spectra are briefly described because most of the discussion in this paper refers to them. Extracting the information presented in this section merely from the reference to the code may not be obvious to all readers. The information in this section however is totally based on IBC 2003 code (International Code Council, 2003). 


\subsection{IBC Site Class}

A "Site Class" specified by letter A, B, C, D, E or F is determined on the basis of the shear wave velocity of soil $\left(v_{s}\right)$ as described in Table 1615.1.1 of IBC 2003 and reproduced here in Table 1 . Standard penetration resistance $(N)$ or the drained shear strength of soil $\left(s_{u}\right)$ may be used to determine the site class where vs is not known. The information about these tests can be found in the code.

Table 1. IBC site class definitions

\begin{tabular}{|l|l|}
\hline Site Class & Shear Wave Velocity $\mathbf{v}_{\mathbf{s}}(\mathbf{m} / \mathbf{s})$ \\
\hline A (Hard Rock) & $v_{s}>1500$ \\
\hline B (Rock) & $760 \geq v_{s} \leq 1500$ \\
\hline C (Soft Rock) & $360 \geq v_{s} \leq 760$ \\
\hline D (Stiff Soil) & $180 \geq v_{s} \leq 360$ \\
\hline E (Soft Soil) & $v_{s} \leq 180$ \\
\hline
\end{tabular}

\subsection{Mapped Spectral Accelerations}

Maximum considered spectral response acceleration for $5 \%$ damping at structural periods of 0.2 and 1.0 seconds are referred to as $S_{S}$ and $S_{1}$, respectively. Figures 1515(1) through 1615(10) of IBC 2003 show these mapped spectral response accelerations for any given geographical location. The maps show the contours of constant values of $S_{S}$ and $S_{1}$. Each contour line is labeled as percentage of $g$. For example, a value of 150 from the maps will be interpreted as $1.5 \mathrm{~g}$. The maps of spectral accelerations given in the code are for USA only. For other countries of the world, agencies and organizations responsible for seismic classification will provide the data.

\subsection{Site Coefficients}

IBC "Site Coefficients" $F_{a}$ and $F_{v}$ are given in Table 2 and Table 3 respectively. For any value of $S_{S}$ that is in between the values of $S_{S}$ for any two columns (shown in the column headings), $F_{a}$ is obtained by linear interpolation. Similarly for any value of $S_{1}$ in between the values given in the column headings, linear interpolation will be required to obtain $F_{v}$.

Table 2. IBC site coefficients $\boldsymbol{F}_{a}$

\begin{tabular}{|c|c|c|c|c|c|}
\hline \multirow{2}{*}{$\begin{array}{l}\text { Site } \\
\text { Class }\end{array}$} & \multicolumn{5}{|c|}{ Coefficient $F_{a}$ from Table 1615.1 2(1) of IBC } \\
\hline & $S_{s} \leq 0.25$ & $S_{\mathrm{s}}=0.50$ & $\mathrm{~S}_{\mathrm{s}}=0.75$ & $S_{s}=1.00$ & $\mathrm{~S}_{s} \geq 1.25$ \\
\hline $\mathrm{A}$ & 0.8 & 0.8 & 0.8 & 0.8 & 0.8 \\
\hline $\mathrm{B}$ & 1.0 & 1.0 & 1.0 & 1.0 & 1.0 \\
\hline $\mathrm{C}$ & 1.2 & 1.2 & 1.1 & 1.0 & 1.0 \\
\hline $\bar{D}$ & 1.6 & 1.4 & 1.2 & 1.1 & 1.0 \\
\hline$E$ & 2.5 & 1.7 & 1.2 & 0.9 & 0.9 \\
\hline
\end{tabular}

\subsection{Design Response Spectrum}

IBC 2003 design response spectrum is shown in Fig. 1. Instructions for generating this design response spectrum are given in the code. It is re-written below as a computer code procedure:
Table 3. IBC site coefficients $F_{v}$

\begin{tabular}{|c|c|c|c|c|c|}
\hline \multirow{2}{*}{ Site } & \multicolumn{5}{|c|}{ Coefficient Fv from Table $1615.1 .2(2)$ of IBC } \\
\cline { 2 - 6 } & $\mathrm{S} 1 \leq 0.1$ & $\mathrm{~S} 1=0.2$ & $\mathrm{~S} 1=0.3$ & $\mathrm{~S} 1=0.4$ & $\mathrm{~S} 1 \geq 0.5$ \\
\hline A & 0.8 & 0.8 & 0.8 & 0.8 & 0.8 \\
\hline B & 1.0 & 1.0 & 1.0 & 1.0 & 1.0 \\
\hline C & 1.7 & 1.6 & 1.5 & 1.4 & 1.3 \\
\hline D & 2.4 & 2.0 & 1.8 & 1.6 & 1.5 \\
\hline E & 3.5 & 3.2 & 2.8 & 2.4 & 2.4 \\
\hline
\end{tabular}

1. Determine IBC site class based on data in Table

2. Determine $\mathrm{S}_{\mathrm{S}}$ and $\mathrm{S}_{1}$ from the maps.

3. Determine site coefficient $F_{a}$ from Table 2 .

4. Determine site coefficient $F_{\pi}$. from Table 3 .

5. Calculate $\mathrm{S}_{\mathrm{MS}}=\mathrm{F}_{\mathrm{a}} \mathrm{S}_{\mathrm{S}}$ and $\mathrm{S}_{\mathrm{Ml}}=\mathrm{F}_{\mathrm{T}} \mathrm{S}_{1}$

6. Calculate $\mathrm{S}_{\mathrm{DS}}=2 \mathrm{~S}_{\mathrm{MS}} / 3$

7. Calculate $\mathrm{S}_{\mathrm{Dl}}=2 \mathrm{~S}_{\mathrm{Ml}} / 3$

8. Calculate $\mathrm{T}_{\mathrm{S}}=\mathrm{S}_{\mathrm{D} 1} / \mathrm{S} \mathrm{DS}$

9. Calculate $\mathrm{T}_{0}=0.2 \mathrm{~T}_{\mathrm{S}}$

10. Calculate $\mathrm{S}_{\mathrm{a}}$ as follows:
a) $\mathrm{T} \leq \mathrm{T}_{0}$ : $\quad \mathrm{S}_{\mathrm{a}}=0.6 \mathrm{~T}\left(\mathrm{~S}_{\mathrm{DS}} / \mathrm{T}_{0}\right)+0.4 \mathrm{SDS}$
b) $T_{0} \leq T \leq T_{S}: S_{2}=S D S$
c) $\mathrm{T}>\mathrm{T}_{\mathrm{S}}: \quad \mathrm{S}_{\mathrm{d}}=\mathrm{S}_{\mathrm{D} 1} / \mathrm{T}$

11. Draw response spectrum as shown in Fig. 1.

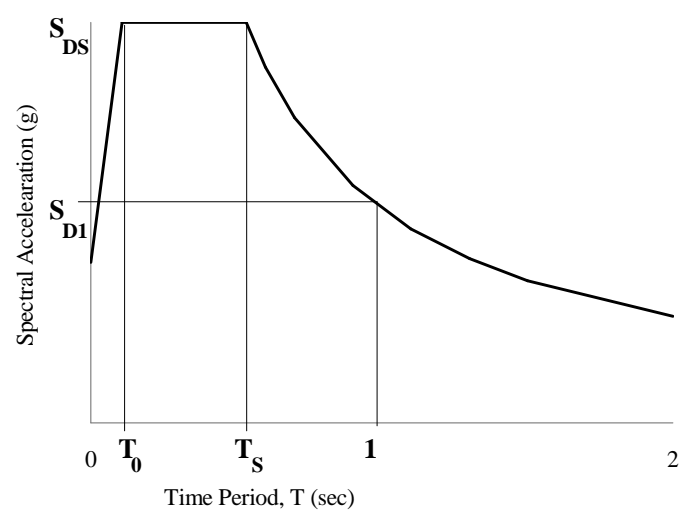

Figure 1. IBC 2003 design response spectrum

\section{Sensitivity of Response Spectra}

Sensitivity of response spectra to the IBC parameters is assessed by generating three different sets of plots. First for a given value of $S_{1}, S_{S}$ is varied. For each value of $S_{S}$, response spectra are generated for all five site classes. Next, for a given value of $S_{S}, S_{1}$ is varied. Again the response spectra are generated for all the five site classes. These curves show the effect of IBC site class. In a similar manner, the effect of $S_{S}$ is shown for a several values of $S_{1}$ and the effect of $S_{1}$ is shown for a several values of $S_{S}$.

A total of eighteen plots, each containing a set of response spectra, were generated for obtaining the sensitivities of response spectra shapes to the IBC parameters. The sensitivities, as observed from these eighteen sets of response spectra, are discussed in the following sections. However, to cut down the size of the paper, only four plots are given here and other similar ones are not included in 
this paper. These plots can however be easily generated for any given values of IBC site class, and the mapped accelerations $S_{S}$ and $S_{1}$ by using the software PPLAN23D.

\subsection{Effect of Site Class}

The effect of IBC site class on the shape of the design response spectra was investigated by plotting design response spectra for all five site classes for a set of values of $S_{S}$ and $S_{1}$. Only, two of these plots are shown in Figs. 2 and 3 . The plots were generated in two groups. One group consisted of plots with $S_{1}=0.8$ and $S_{S}=2.5,2.0,1.9$ and 1.7 and the other group consisted of plots with $S_{S}=$ 1.5 and $S_{1}=0.7,0.8,0.9$ and 1.0 .

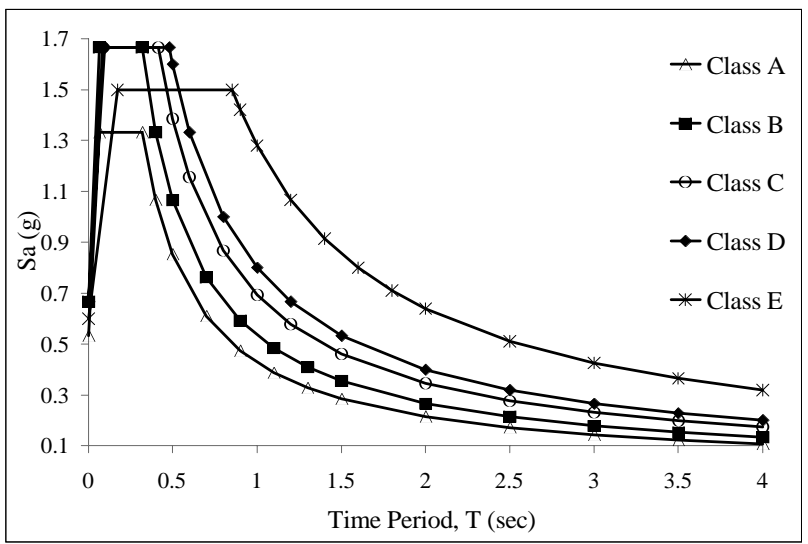

Figure 2. Sensitivity of IBC site class $\left(S_{I}=0.8 g\right.$, $\left.S_{S}=2.5 g\right)$

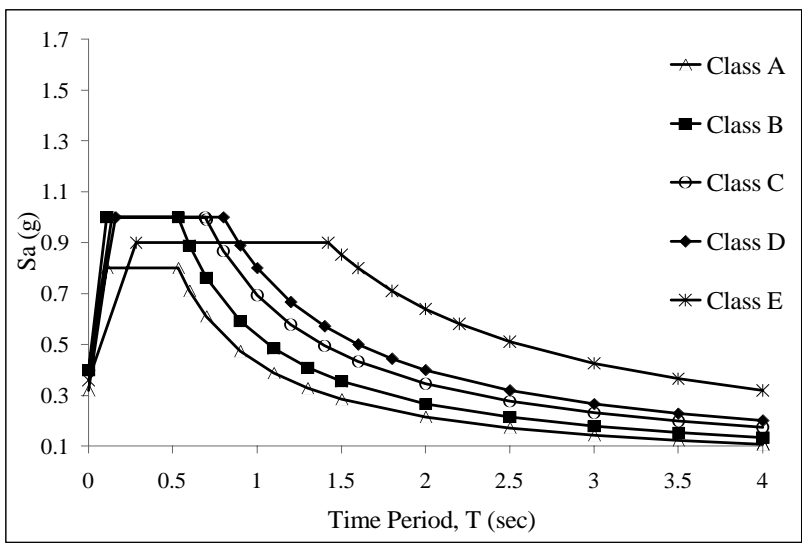

Figure 3. Sensitivity of IBC site class $\left(S_{1}=\mathbf{0 . 8 g}\right.$,

$$
\left.S_{S}=1.5 \mathrm{~g}\right)
$$

From these plots, it is observed that within the critical range of short time periods, design response spectra for class B, C and D have the same peak acceleration and Class A design spectrum has always smaller peak acceleration as compared to all other site classes. Other than the insensitivity of the design response spectra in the short acceleration region for class $\mathrm{B}, \mathrm{C}$ and $\mathrm{D}$, the design response spectrum is sensitive to the site class for all sets of values of $S_{S}$ and $S_{1}$.

\subsection{Effect of Short Period $S_{S}$}

The effect of $S_{S}$ on the shape of the design response spectra was assessed by plots of sets of design response spectra for a given site class and a given value of $S_{1}$ with different values of $S_{S}$. A typical plot of this type, for IBC site class B and $S_{1}=0.8$, is shown in Fig. 4 .

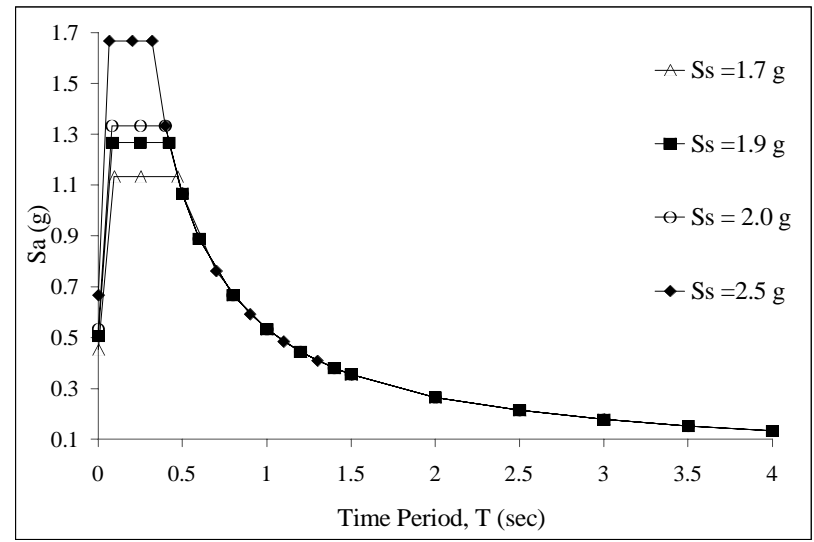

Figure 4. Sensitivity of $S_{S}$ (IBC site class $B, S_{1}=$ $\left.0.8_{g}\right)$

From plots of this type, for all site classes, it becomes obvious that only the peak acceleration is affected by varying the value of $S_{S}$. Other than the peak acceleration, the design response spectra coincide for all values of SS and show insensitivity to the variations in $S_{S}$. This insensitivity to $S_{S}$ is rather unexpected. Thus, for buildings with the fundamental time period of around $0.6 \mathrm{sec}, S_{S}$ is immaterial. Also, it was observed from observing all the sets of curves for all site classes that the design response spectra peak acceleration area widens as we move from site class A to site class E. This implies that softer soil will result in larger internal moments and buildings of a wider range of fundamental time period will be affected.

\subsection{Effect of Long Period $S_{1}$}

The third type of plots included sets of design response spectra for a given site class and a given value of $S_{S}$ with varying values of $S_{1}$. Sets of such curves were generated for all the five site classes. These plots show the sensitivities of response spectra to $S_{1}$. A typical plot of this type (for IBC site class D, $S_{S}=2.0$ ) is shown in Fig. 5 .

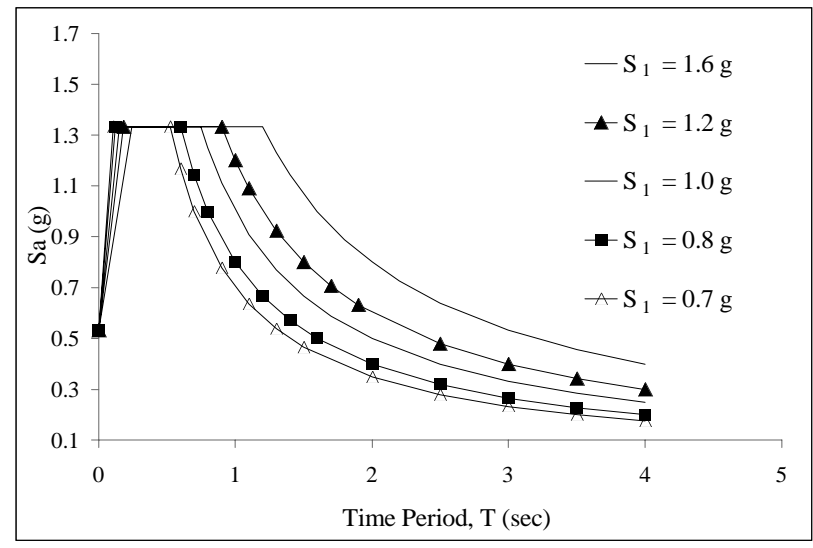

Figure 5. Sensitivity of $S_{1}$ (IBC site class D, $S_{S}=$ $2.0_{\mathrm{g}}$ ) 
From plots of this type, for all site classes, it was concluded that for a given site class, the design response spectra always have the same peak acceleration for all values of $S_{1}$. In other words the value of peak acceleration is insensitive to $S_{1}$ for a given site class. For time periods beyond the peak accelerations the spectral accelerations become sensitive to variations in S1 but the effect is not so obvious and seems linear. However, it is not possible to make a judgment in this regard from these curves. Its effect will become more obvious from the plots showing the sensitivity of maximum moment to $S_{1}$ presented in the following sections.

\section{Building Models}

Although a number of reinforced concrete buildings were analyzed, only four cases are presented in this paper. The first case is not a real building but was designed as an academic exercise. The three other cases selected from the existing buildings of the third world. The data for these three cases were obtained from the maps of the buildings. These four cases of low rise buildings are studied to evaluate the sensitivity of internal forces to the IBC parameters. They are described in the following paragraphs:

\subsection{Case1: Building A}

The three dimensional structural model of Building A is shown in Fig. 6. Obviously, this is not a real-world building but simply an academic problem. It was studied and the sensitivities were obtained because some of the characteristics may be easily understood from such a simple building. It is a four story building with two $4 \times 6$ meters rooms on each floor. Each floor has a height of four meters. All columns and beams have the same section of $20 \times 40 \mathrm{~cm}$. Columns oriented so that the larger dimension of the section is along the direction of earthquake excitation which is along Y-axis. In addition to the mass of structural members, a total of $1177 \mathrm{Kg} / \mathrm{m}^{2}$ of mass were assumed to represent the slab dead and live loads. Its fundamental mode of vibration was found to have the time period of 2.48 seconds. Table 4 shows time periods and modal participating mass ratios for each of the 10 modes.

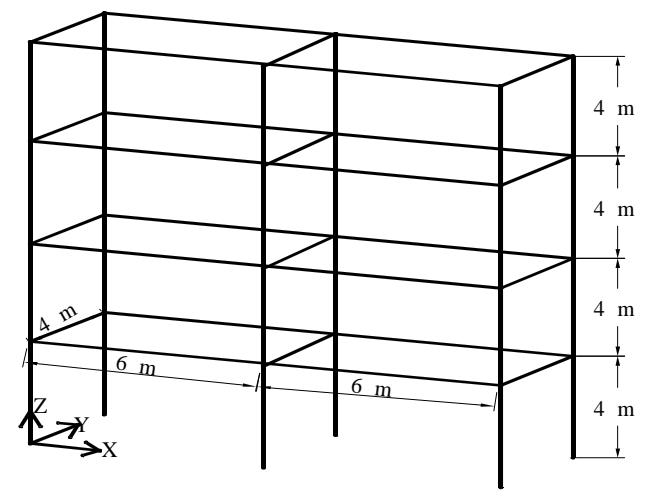

Figure 6. Structural model for Building A
Table 4. Participating mass ratios for Building A

\begin{tabular}{|c|c|c|c|c|}
\hline \multirow{2}{*}{ Mode } & \multirow{2}{*}{$\begin{array}{c}\text { Period } \\
\text { (sec) }\end{array}$} & \multicolumn{3}{|c|}{ Mass Participation (\%) } \\
\hline & & $\mathrm{x}$-axis & $y$-axis & \\
\hline 1 & 2.481839 & 0.0000 & & 0.0000 \\
\hline 2 & & 79.57 & & \\
\hline 3 & & & & \\
\hline 4 & & 0 & & \\
\hline 5 & & & & \\
\hline 6 & & 13.1 & & \\
\hline 7 & & 0.0 & & \\
\hline 8 & & 0.00 & & 0.000 \\
\hline 9 & & 0.00 & & 0.000 \\
\hline 10 & 0.329210 & 0.0000 & 0.9871 & \\
\hline & - & 92.6960 & 99.6986 & 0.00 \\
\hline
\end{tabular}

\subsection{Case 2: Building B}

The floor plan for the Building B of case 2 is shown in shown in Fig. 7. It is a four story concrete building. Its data are given in Table 5 and its 3 -D structural model is shown in Fig. 8. Table 6 shows the time periods and modal participating mass ratios for each of the first ten modes.

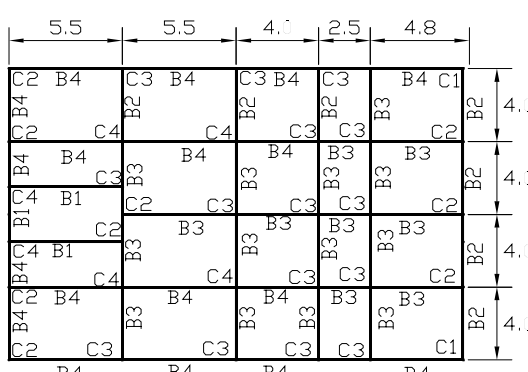

Figure 7. Building B floor plan (Dimensions in meters)

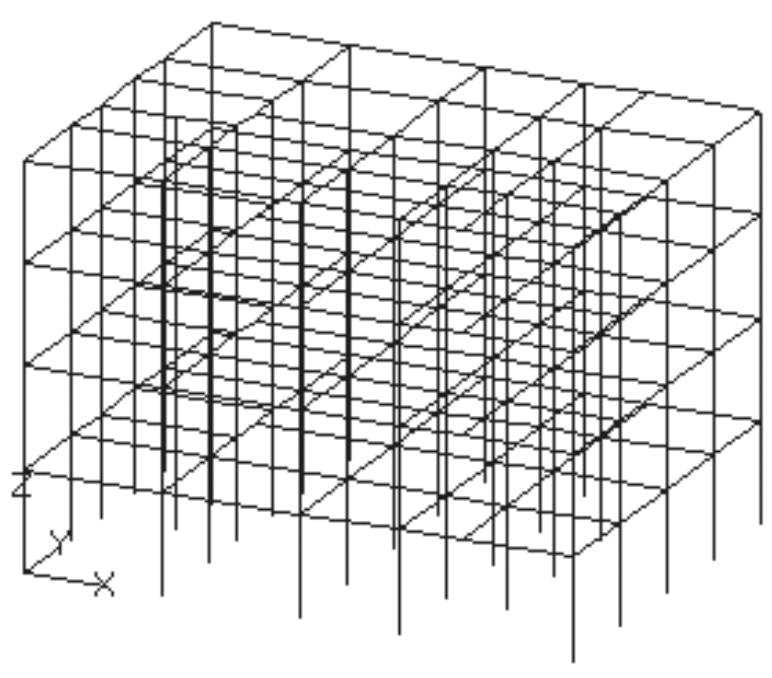

Figure 8. Structural model of Building B 
Table 5. Structural data for Building B

$\begin{array}{lc}\text { Story Height } & \begin{array}{c}\text { 4m (Same of all } \\ \text { floor) }\end{array} \\ & \text { B1: } 20 \mathrm{~cm} \mathrm{X} 90 \mathrm{~cm} \\ \text { Beam Section s } & \text { B2: } 20 \mathrm{~cm} \mathrm{X} 70 \mathrm{~cm} \\ & \text { B3: } 20 \mathrm{~cm} \mathrm{X} 40 \mathrm{~cm} \\ & \text { B4: } 12 \mathrm{~cm} \mathrm{X} 60 \mathrm{~cm} \\ & \text { C1: } 20 \mathrm{~cm} \mathrm{X} 90 \mathrm{~cm} \\ \text { Column Section s } & \text { C2: } 20 \mathrm{~cm} \mathrm{X} 80 \mathrm{~cm} \\ & \text { C3: } 20 \mathrm{~cm} \mathrm{X} 70 \mathrm{~cm} \\ & \text { C4: } 20 \mathrm{~cm} \mathrm{X} 60 \mathrm{~cm} \\ \text { Dead Load } & 977 \mathrm{Kg} / \mathrm{m}^{2} \\ \text { Live load } & 200 \mathrm{Kg} / \mathrm{m}^{2} \\ \text { Excitation Direction } & \text { Horizontal }(\text { Along X) }\end{array}$

Table 6. Participating mass ratios for Building B

\begin{tabular}{ccccc} 
Mode & $\begin{array}{c}\text { Period } \\
\text { (sec) }\end{array}$ & \multicolumn{3}{c}{ Mass Participation (\%) } \\
x-axis & y-axis & vertical \\
1 & 2.452523 & 0.0000 & 81.3266 & 0.0000 \\
2 & 1.511711 & 0.0004 & 1.5401 & 0.0000 \\
3 & 1.282251 & 74.9151 & 0.0000 & 0.0004 \\
4 & 0.763149 & 0.0000 & 10.9075 & 0.0000 \\
5 & 0.498438 & 0.0001 & 0.2364 & 0.0000 \\
6 & 0.412277 & 0.0000 & 4.2719 & 0.0000 \\
7 & 0.397150 & 0.0001 & 0.0020 & 0.0000 \\
8 & 0.316919 & 0.0010 & 0.1535 & 0.0000 \\
9 & 0.307761 & 16.5303 & 0.0000 & 0.0028 \\
10 & 0.303859 & 0.0000 & 0.0051 & 0.0000 \\
Sums & ----------- & 91.4471 & 98.4431 & 0.0033
\end{tabular}

\subsection{Case 3: Building C}

The building floor plan for this three-story concrete building is shown in Fig. 9 and its 3-D structural model is shown in Fig. 10 and the data related to the building is shown in Table 7. Table 8 shows the time periods and the modal participating mass ratios for the first ten frequencies.

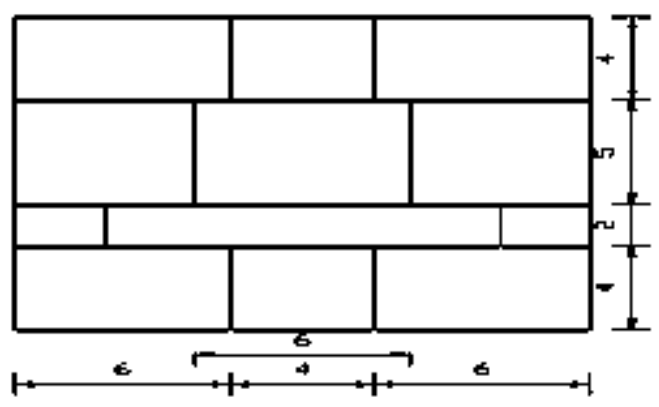

Figure 9. Building C floor plan (Dimensions in meters)

\subsection{Case 4: Building D}

The building floor plan for this four-story building is shown in Fig. 11 and its 3-D structural model is shown in Fig. 12. The data related to the building is shown in Table 9. Table 10 shows modal participating mass ratios for the first 10 frequencies.

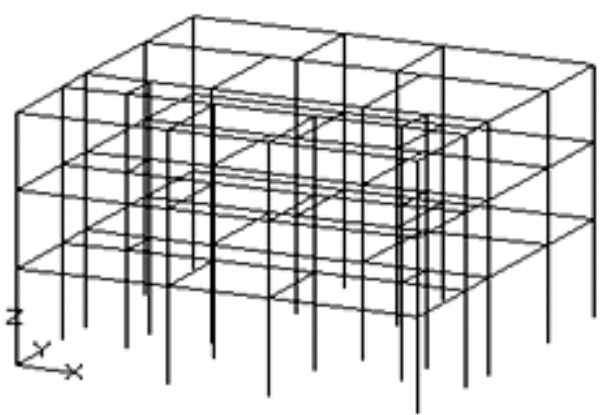

Figure 10. Structural model of Building C

Table 7. Structural data for Building C

$\begin{array}{ll}\text { Story Height } & \text { Floor 1: 5m, Floors } 2 \text { \&3: 4m } \\ \text { Beams section } & \text { B1: 20x60 } \\ \text { Column section } & \text { C1: 20x70, C2: 20x60, C3:20x30 } \\ \text { Dead load } & 977 \mathrm{Kg} / \mathrm{m}^{2} \\ \text { Live load } & 200 \mathrm{Kg} / \mathrm{m}^{2} \\ \begin{array}{l}\text { Excitation } \\ \text { direction }\end{array} & \text { Horizontal (Along X) }\end{array}$

Table 8. Participating mass ratios for Building C

\begin{tabular}{ccccc} 
Mode & Period & \multicolumn{3}{c}{ Mass Participation (\%) } \\
& (sec) & x-axis & $\begin{array}{c}\text { y-axis } \\
\text { z-axis }\end{array}$ \\
1 & 1.931639 & 0.0000 & 92.6450 & 0.0000 \\
2 & 1.288993 & 23.6038 & 0.0000 & 0.0000 \\
3 & 1.085399 & 60.7300 & 0.0000 & 0.0000 \\
4 & 0.601114 & 0.0000 & 6.4904 & 0.0000 \\
5 & 0.386256 & 0.4550 & 0.0000 & 0.0000 \\
6 & 0.342578 & 0.0000 & 0.8182 & 0.0000 \\
7 & 0.324441 & 0.0010 & 0.0000 & 0.0000 \\
8 & 0.304040 & 11.2648 & 0.0000 & 0.0000 \\
9 & 0.268213 & 0.0000 & 0.0022 & 0.0000 \\
10 & 0.249552 & 0.0783 & 0.0000 & 0.0000 \\
Sums & ---------- & 96.1329 & 99.9558 & 0.0000
\end{tabular}

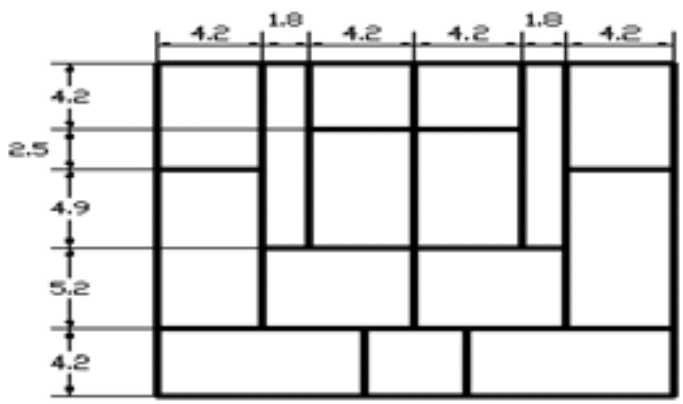

Figure 11. Building D floor plan (Dimensions in metres

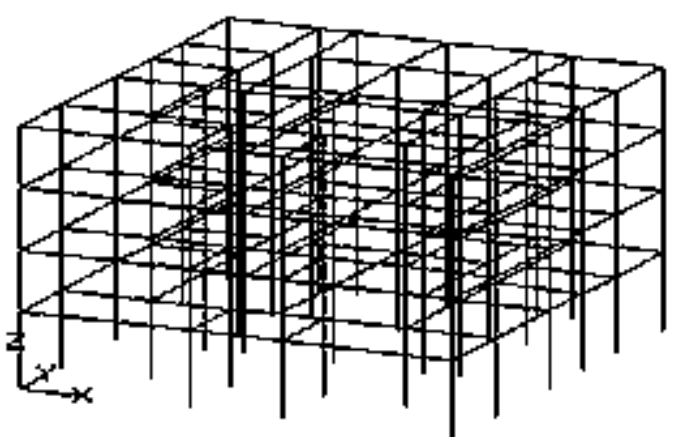

Figure 12. Structural model of Building D 
Table 9. Structural data for Building D

$\begin{array}{ll}\text { Story Height } & \text { Floor 1:5m, Floors 2-4: 4m } \\ \text { Beams Section } & \text { B1:20 X 60 } \\ \text { Column Section } & \text { C1:20 X 70, C2:20 X 60 } \\ \text { Dead Load } & 977 \mathrm{Kg} / \mathrm{m}^{2} \\ \text { Live load } & 200 \mathrm{Kg} / \mathrm{m}^{2} \\ \text { Excitation Direction } & \text { X- Direction (Horizontal 1) }\end{array}$

Table 10. Participating mass ratios for Building $D$

\begin{tabular}{ccccc} 
Mode & $\begin{array}{c}\text { Period } \\
\text { (sec) }\end{array}$ & \multicolumn{3}{c}{ Mass Participation (\%) } \\
& x-axis & y-axis & z-axis \\
1 & 2.686017 & 0.0000 & 90.1560 & 0.0000 \\
2 & 1.696465 & 18.5077 & 0.0021 & 0.0000 \\
3 & 1.536623 & 63.0913 & 0.0004 & 0.0000 \\
4 & 0.848023 & 0.0000 & 7.8133 & 0.0001 \\
5 & 0.553572 & 0.0653 & 0.0005 & 0.0000 \\
6 & 0.503251 & 0.0012 & 0.0000 & 0.0000 \\
7 & 0.472579 & 0.0000 & 1.6927 & 0.0001 \\
8 & 0.424656 & 13.1580 & 0.0000 & 0.0000 \\
9 & 0.362340 & 0.0359 & 0.0004 & 0.0000 \\
10 & 0.344050 & 0.1251 & 0.0000 & 0.0000 \\
Sums & ----------- & 94.9846 & 99.6654 & 0.0002
\end{tabular}

\section{Discussion of Results}

The sensitivity data was generated for the four buildings as described in the previous section. The results obtained for these four building cases are presented here. Similar results, for other building cases, are not presented here due to limitation of number of pages. For each of these four cases, the sensitivity curve was generated by keeping two of the parameters constant and varying the third one. For example, to obtain the Site Class sensitivity, certain typical values of $S_{S}$ and $S_{1}$ were chosen and site class was varied. The design response spectrum was obtained for each of the values of the site class and the maximum moment in the structure was obtained from structural analysis based on the IBC compliant design response spectrum using the computer programs PLAN23D and SAP2000. PLAN23D generated the structural models as well as the IBC compliant design response spectra and produced error-free input data files for the software SAP2000 which was used to obtain the internal forces in structural members.

For all the four building cases, similar exercises were repeated for obtaining the sensitivity of maximum moment to $S_{S}$ and $S_{1}$. In the case of $S_{S}$, a typical value of S1 was selected and curves were generated for maximum moment versus SS for all the five site classes for all four cases. Similarly, to obtain the sensitivity of maximum moment to $S_{1}$, a typical value of $S_{S}$ was selected arbitrarily and again curves were generated for maximum moment versus $S_{S}$ for all the five site classes. The results are discussed in the following sections.

\subsection{Site Class Sensitivity}

Sensitivity of maximum moment to the site class is shown in Fig. 13 for all the four cases. The figure also shows, for each building, the moment capacity of the structural member that was found to have the maximum predicted bending moment. This makes the data more meaningful and useful for practicing engineers.

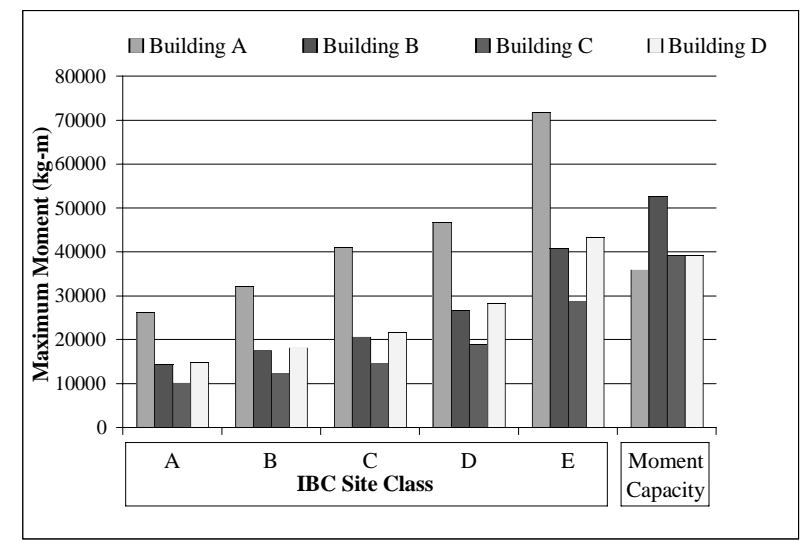

Figure 13. IBC site class sensitivity

It is obvious from these figures that IBC site class parameter affects the predicted moment significantly and as mentioned earlier, the predicted maximum bending moments increases for softer soils since IBC site class A represents "hard rock" and class E represents soft soil. Thus, due to the high sensitivity of predicted maximum moment to the site class, this parameter must be determined as exactly as possible. Here a weakness in the code provisions becomes apparent. The code provides discrete values of the site class and the code has no provision to allow site class as a continuous variable. With the high sensitivity of the predicted moment to this parameter, the discrete values of IBC site class may lead to errors. For example, we see in Fig. 12 that the maximum moment will for Building A as $71825 \mathrm{~kg}-\mathrm{m}$ even though the shear wave velocity of the soil is only marginally inside the range for site class $\mathrm{E}$ where as if there were a continuous function for the site class, a value slightly higher than $46765 \mathrm{~kg}-\mathrm{m}$ might have been the predicted moment. This will make the maximum moment grossly over-estimated. And conversely, a wrong estimate of the site class may cause the site class to be $\mathrm{D}$ instead of $\mathrm{E}$, resulting in a dangerously low estimate of the maximum moment.

6.2 Short Period Acceleration Sensitivity

Sensitivity of the maximum moment to the short period acceleration $S_{S}$ (IBC parameter) is shown in Figs. 14 to 17 for the four cases. It becomes obvious from these figures showing the sensitivity of moments to $S_{S}$ that the maximum moment is insensitive to this important IBC parameter except for the site class E. This implies that any errors in the evaluation of this parameter will not affect the design of the structure. However, the insensitivity of this important parameter may represent an error in the IBC code. 
The Journal of Engineering Research Vol. 6, No. 1 (2009) 66-75

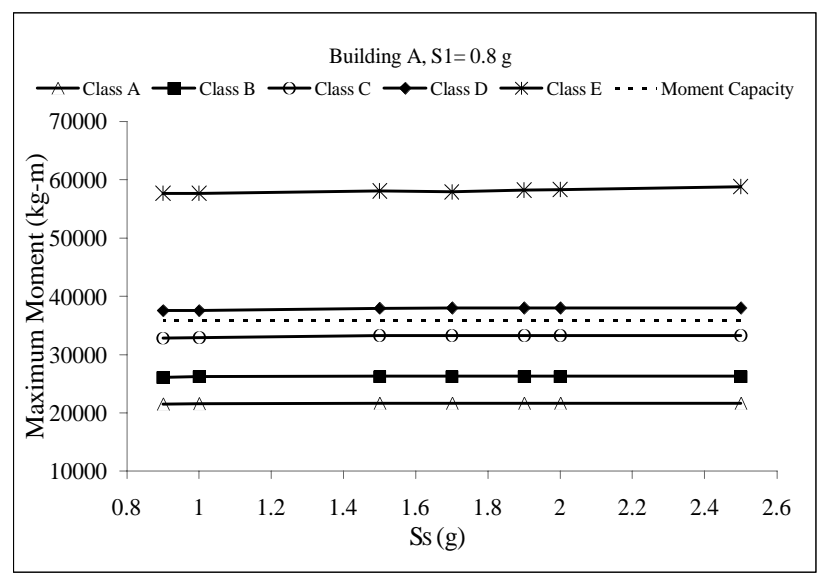

Figure 14. Sensitivity of moment to $S_{S}$ (Building A)

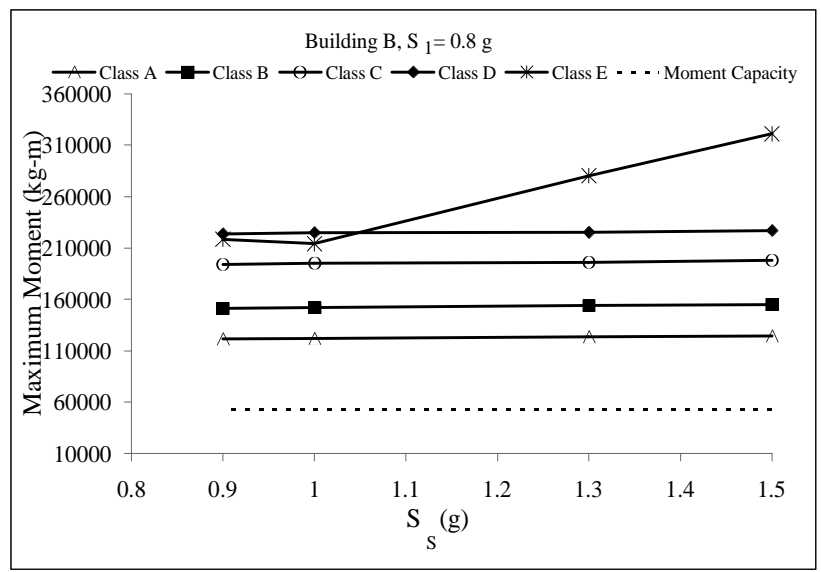

Figure 15. Sensitivity of moment to $S_{S}$ (Building B)

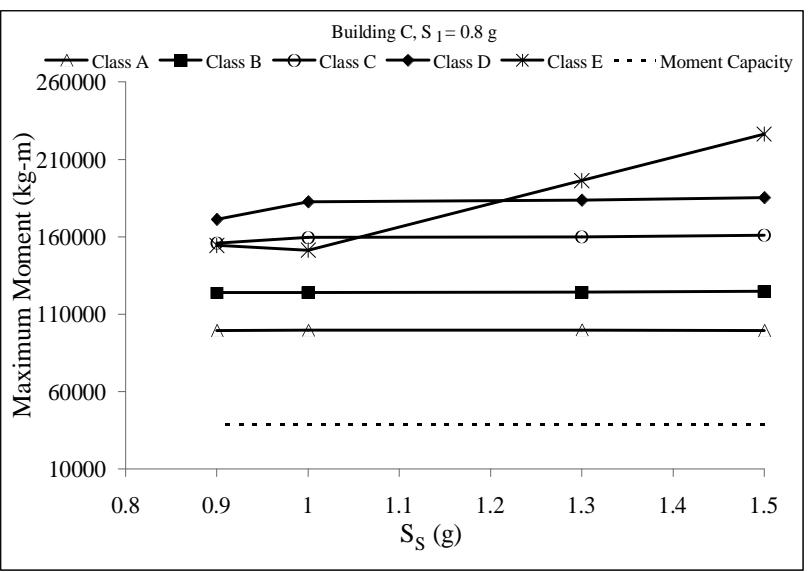

Figure 16. Sensitivity of moment to $S_{S}$ (Building C)

Since the plots show the moment capacity of the structural member subjected to the maximum bending moment by a dotted line, it can be easily seen if the buildings will be safe during an earthquake or not. The plot for Building A which does not represent a real building but was designed as an academic exercise clearly indicates that it is safe if built on soil of type IBC site class A, B or C but will be unsafe if built on softer soil that fall in the category of IBC site class D and E.

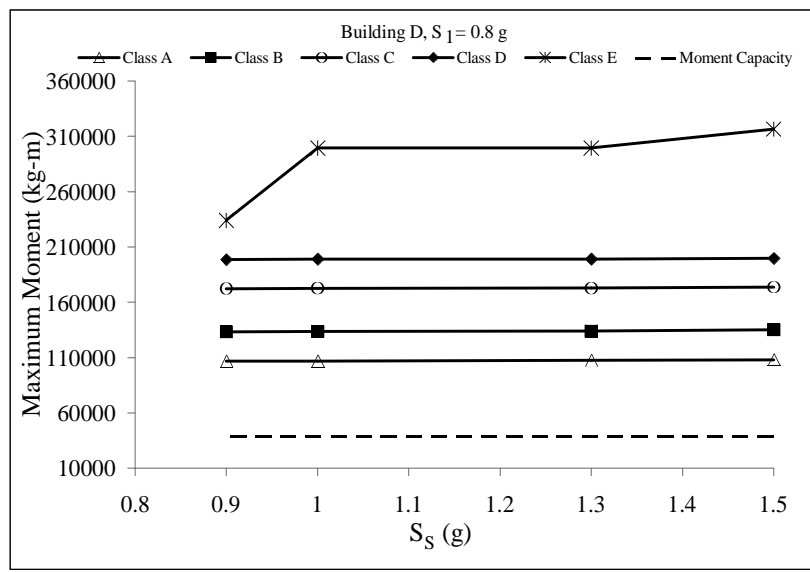

Figure 17. Sensitivity of moment to $S_{S}$ (Building D)

On the other hand all the three real buildings namely Buildings B, C and D have predicted bending moments much larger than the moment capacity. This may mean that the selected buildings are not well designed. In fact, it is true that most residential buildings are not designed for seismic loads specially in the third world countries. This conclusion that is eaily seen from the presented curves is important for authorities to take a look and evaluate the safety of residential low rise buildings for earthquakes.

Another minor observation relates to the sensitivity for site class E as compared to other site classes. It exhibits differently from other classes and indicates that maximum moment has some sensitivity to $S_{S}$ become steeper for higher values of $S_{S}$.

\subsection{Long Period Acceleration Sensitivity}

For the four building cases, sensitivity of the maximum moment to the IBC parameter, namely long period acceleration $S_{1}$ is shown in Figs. 18 to 21. The maximum moment is not insensitive to this IBC parameter. It has quite significant sensitivity. This implies that any errors in the evaluation of this parameter will definitely affect the design of the structure.

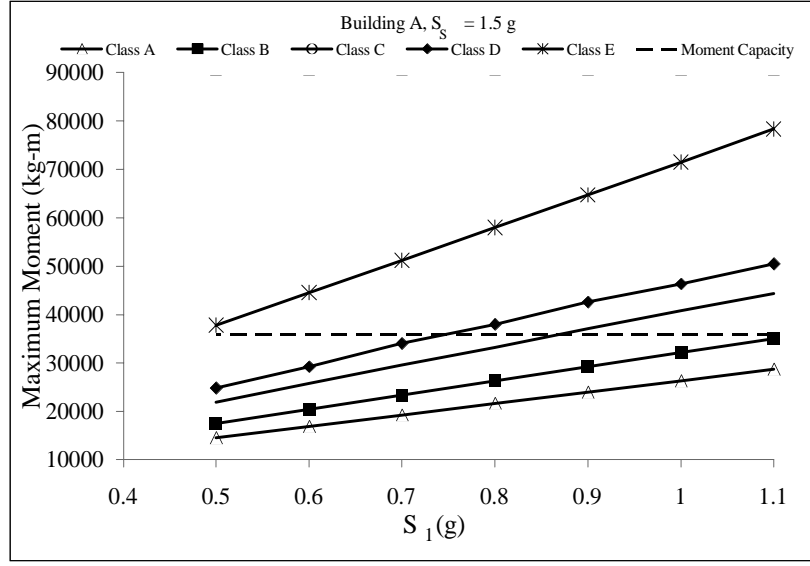

Figure 18. Sensitivity of moments to $S_{1}$ (Building A) 


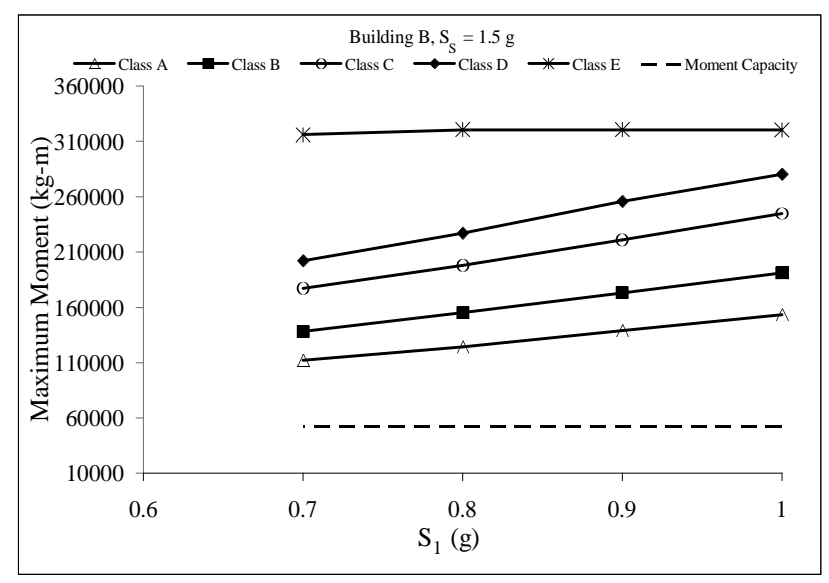

Figure 19. Sensitivity of moment to $S_{1}$ (Building B)

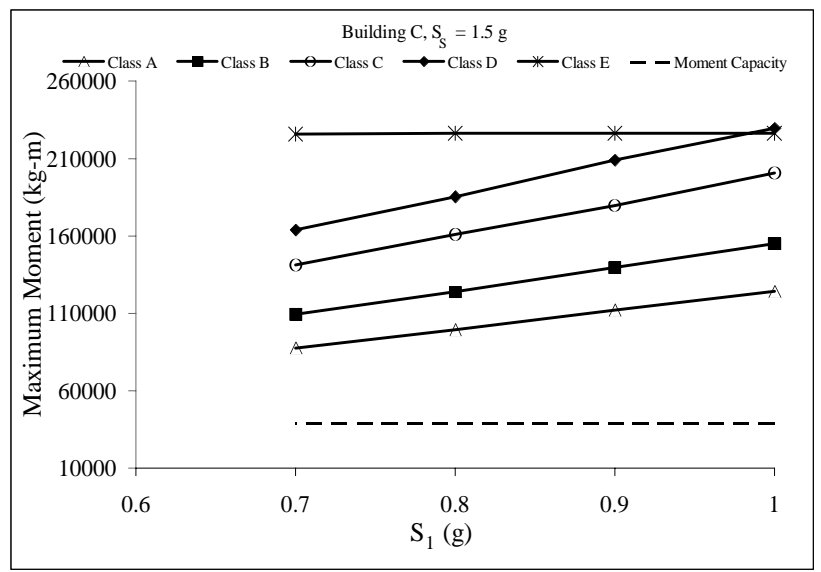

Figure 20. Sensitivity of moment to $S_{1}$ (Building C)

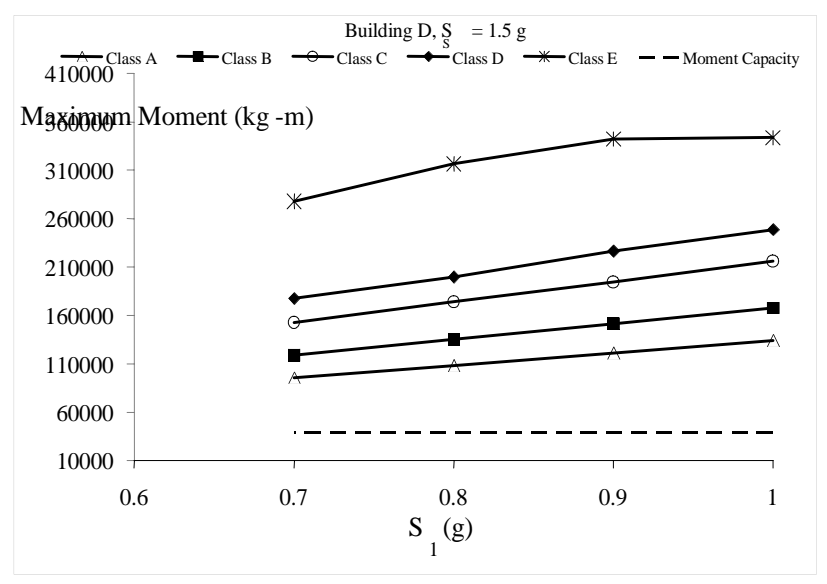

Figure 21. Sensitivity of moment to $S_{1}$ (Building D)

It is interesting to note from these sensitivity curves that the relationship between maximum moment and long period acceleration is very close to being linear. This suggests that IBC code may be improved by providing a linear relationship, so that the error in the estimate of the maximum moment due to variation in the value of $S_{1}$ may be easily estimated. This will help the practicing engineers in exploring the possibilities of designing similar buildings at different geographical locations that have different seismic activity.

\section{Conclusions}

The paper presents data giving the sensitivity of structural response to the variations in the IBC-compliant response spectra. From the data presented in this paper, the following conclusions are made:

The design spectra for the IBC site class B, C and D have approximately the same peak acceleration for short time periods but class A has a clearly visible lower value.

Within the critical range of short time periods, class A design spectrum has always smaller peak acceleration as compared to that of Class B, C and D. The variation is not uniform. Only the peak acceleration is affected by varying the value of $S_{S}$. Thus, for buildings with the fundamental time period of around $0.8 \mathrm{sec}, S_{S}$ is immaterial.

The design response spectra are almost identical in the range of short periods for all values of $S_{1}$.

The site class affects the computed moment significantly and thus this parameter must be determined as exactly as possible. However, the code provides discrete values of the site class and the code has no provision that allows site class as a continuous variable.

The maximum moment is insensitive to $S_{S}$ except for the site class E. This implies that any error in the evaluation of this parameter will not affect the design of the structure.

The maximum moment has a quite significant sensitivity to $S_{1}$. This implies that any error in the evaluation of this parameter will definitely affect the design of the structure. The relationship between the maximum moment and the long period acceleration is very close to being linear.

The data and the results presented in the paper are useful in understanding the impact of IBC code provisions and the output of response spectrum analysis. It also serves as an example and points to a lack of such data in the published literature. The presented technique used in generating the data is also useful from academic point of view and will help the researchers in accomplishing their computational experiments required to understand structural response of multi-story buildings in a manner that is fast, easy and error-free.

\section{References}

Anagnostopoulos, S., Demopoulos, A., 2003, "Preliminary Assessment of a Simplified Code Method for Earthquake Design Of Asymmetric Buildings", Proc. Concrete Structures in Seismic Regions: FIB 2003 Symposium.

Chopra, A. K., Goel, R. K, 2001, "A Modal Pushover Analysis Procedure for Estimating Seismic Demands for Buildings", Earthquake Engineering \& Structural Dynamics, Vol. 31(3), pp. 561 - 582.

Computer \& Structures Inc, 2005, "SAP2000 Software Package", http://www.csiberkeley.com, California, USA. 
Engineering Optimization Software, 2007, "PLAN23D User's Manual", www.planopt.com, Georgia, USA.

Hooper, J. D., 2006, "General Seismic Design Requirements For Buildings", Proc. 100th Anniversary Earthquake Conference.

International Code Council Inc., 2003, "International Building Code 2003”, Falls Church, Virginia.

International Conference of Building Officials, 1997, "Uniform Building Code", Whittier, California.
Nahhas, T. M., Imam M. H. 2001, "Three-Dimensional Structural Modeling of Multi-Storey Buildings for Obtaining Moment Envelopes", Proceedings of Eighth International Conference on Civil and Structural Engineering Computing.

Wilkinson S, Thambiratnam D., 2001, "Simplified Procedure for Seismic Analysis of Asymmetric Buildings", Computers and Structures, 79:2833-2845. 